\title{
Preparation and thermomechanical properties of stir cast Al-2Mg-11TiO 2 (rutile) composite
}

\author{
S K CHAUDHURY*, A K SINGH, C S S SIVARAMAKRISHNAN and S C PANIGRAHI ${ }^{\dagger}$ \\ National Metallurgical Laboratory, Jamshedpur 831 007, India \\ ${ }^{\dagger}$ Department of Metallurgical and Materials Engineering, Indian Institute of Technology, Kharagpur 721 302, India \\ *Present Address: 100 Institute Road, MPI, WPI, Worcester, MA 01609, USA
}

MS received 15 April 2004; revised 14 September 2004

\begin{abstract}
Al-2Mg-11TiO 2 composite was successfully prepared by the conventional vortex method. The macrostructural observation revealed columnar structure with rutile particles being distributed throughout the matrix in the form of agglomerates. Microstructural observation showed the presence of micro voids in the particle-enriched zone. Electrical resistivity measurement showed a phase transformation at $360^{\circ} \mathrm{C}$, which was consistent during DSC studies due to the precipitation of $\mathrm{TiAl}_{3}$ phase. As-cast composite was both hot rolled and cold rolled successfully to 50 and $40 \%$ reduction, respectively. The mechanical properties of the thermomechanically-worked composite were studied. From fractographic analysis, it was clear that the crack had nucleated at the particle/matrix interface and propagated through the matrix by microvoid coalescence. Ultimate tensile strength of cold worked composite was found to be better than the hot worked material.
\end{abstract}

Keywords. Metal matrix composites; stir cast; rutile.

\section{Introduction}

The need for the lightweight materials having high strength and high stiffness in automotive and aerospace application have generated considerable interest to develop $\mathrm{Al}$ based metal matrix composites (Rohatgi 1991). Among the various methods to fabricate metal matrix composites, liquid metallurgy vortex method has drawn keen attraction among the researchers due to its industrial feasibility. The major limitation in many cases in fabricating metal matrix composites by liquid phase route resides upon the incompatibility of the reinforcement and the matrix (Alonso et al 1993). This problem in case of Albased metal matrix composite is due to the formation of stable tenacious oxide film, resulting in poor wettability with the ceramic particle (Chu and Wu 1999). One of the common practice to improve wettability of an $\mathrm{Al}$ melt is through addition of small amount of reactive metals like magnesium, titanium etc (Rohatgi et al 1986) prior to the incorporation of ceramic particle. In the present work, 2 wt\% magnesium was added to Al to improve wettability.

The objectives of the present investigation were to prepare $\mathrm{Al}-2 \mathrm{Mg}-11 \mathrm{TiO}_{2}$ by liquid metallurgy vortex method and study its thermomechanical behaviour through metallography. Physical properties were also measured. Fractured surfaces of the composites were also studied under scanning electron microscope and the observations were

*Author for correspondence correlated with the tensile properties. Electrical resistivity and differential scanning calorimetric studies were carried out to understand the effect of ageing on the mechanical properties of the composite.

\section{Experimental}

$500 \mathrm{~g}$ of commercial grade $\mathrm{Al}(99.8 \%)$ was taken to prepare the composite by stir casting. The average size of rutile powder used in this work was $113 \mu \mathrm{m}$ with a standard deviation of $38 \mu \mathrm{m}$. This size range was chosen because with finer particles $(<20 \mu \mathrm{m})$ rejection rate was very high and only limited amount could be retained in the melt (Maity et al 1995). Al was melted in electric resistance furnace and the temperature was maintained at $800^{\circ} \mathrm{C}$. A known amount of rutile powder (preheated to $200^{\circ} \mathrm{C}$ ) was added, while the melt was stirred with a graphite stirrer at a rotation speed of $200 \mathrm{rpm}$. Prior to powder addition, about $2 \mathrm{wt} \%$ magnesium was plunged into the melt to increase wettability of the melt. Technical details of the process is described elsewhere (Maity et al 1993). Density of both as-cast and mechanically worked composite was measured using Archimedes' principles. The resulting densities are shown in table 1 with calculated volume fractions of porosity.

Electrical resistivity as a function of temperature was measured by a d.c. four-probe method in an electrical resistivity unit (TER-2000, Ulvac/Sinku-Rico, Japan), where the temperature was varied from $50-500^{\circ} \mathrm{C}$. The dimension of the specimen for resistivity measurement was 
$20 \times 3 \times 0.65 \mathrm{~mm}$. The calorimetric study was carried out using a Perkin-Elmer DSC-7 calorimeter. The rate of heating was $10^{\circ} \mathrm{C} / \mathrm{min}$ in case of both resistivity and DSC measurements. Isothermal electrical resistivity was done at the temperature corresponding to the onset of physical transformation for $30 \mathrm{~min}$. The X-ray diffractograms of the composite were taken using Siemens-D500 diffractometer using $\mathrm{CoK}_{\alpha}$ radiation. The microstructural characteristics were studied using optical microscope (Lietz make). Ageing was conducted at $300^{\circ} \mathrm{C}$ and $400^{\circ} \mathrm{C}$ in a resistance furnace by holding the thermomechanically processed composite samples for various intervals of time and then quenching in oil. Hardness was measured using a standard Vicker's hardness testing machine by applying $1 \mathrm{~kg}$ load. Tensile testing was done in Honsfield tensometer at the crosshead speed of $3 \mathrm{~mm} / \mathrm{min}$. Fractographic analysis of the thermomechanically processed composite materials was studied under scanning electron microscope (Jeol JCXA 733 analyser).

\section{Results and discussion}

\subsection{Processing and structure}

The composite was cast in a rectangular cast iron die (preheated at $600^{\circ} \mathrm{C}$ ) of dimension $120 \times 65 \times 9 \mathrm{~mm}$. Macrostructural observations (figure 1) revealed columnar structure with finer structure at the top and bottom of the casting and coarser equiaxed in the centre region. The optical micrograph of as cast composite showed considerable segregation of particles. Particles were agglomerated in the form of cluster within microvoids (figures 2a,b). The porosity level was greatly reduced by hot and cold rolling as shown in figures $3 \mathrm{a}$ and $\mathrm{b}$, respectively. This is reflected in the increase of density of the mechanically worked composite as shown in table 1.

The back scattered image and line profile of $\mathrm{Al}, \mathrm{Ti}, \mathrm{Mg}$ and $\mathrm{O}$ across $\mathrm{TiO}_{2}$ particle in the composites are shown in figures $4 \mathrm{a}-\mathrm{e}$. It indicates preferential segregation of $\mathrm{Mg}$ at the interface. This is due to the formation of $\mathrm{Al}_{2} \mathrm{MgO}_{4}$ during preparation of the composite. The formation of $\mathrm{Al}_{2} \mathrm{MgO}_{4}$ spinels is due to the in situ reaction between liquid $\mathrm{Al}$ and $\mathrm{TiO}_{2}$ particles.

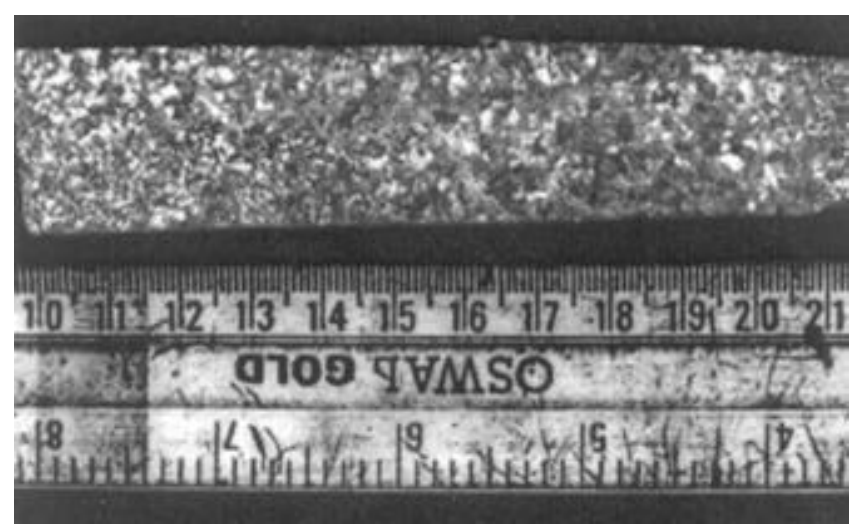

Figure 1. Macrograph of stir cast $\mathrm{Al}-2 \mathrm{Mg}-11 \mathrm{TiO}_{2}$ composite.
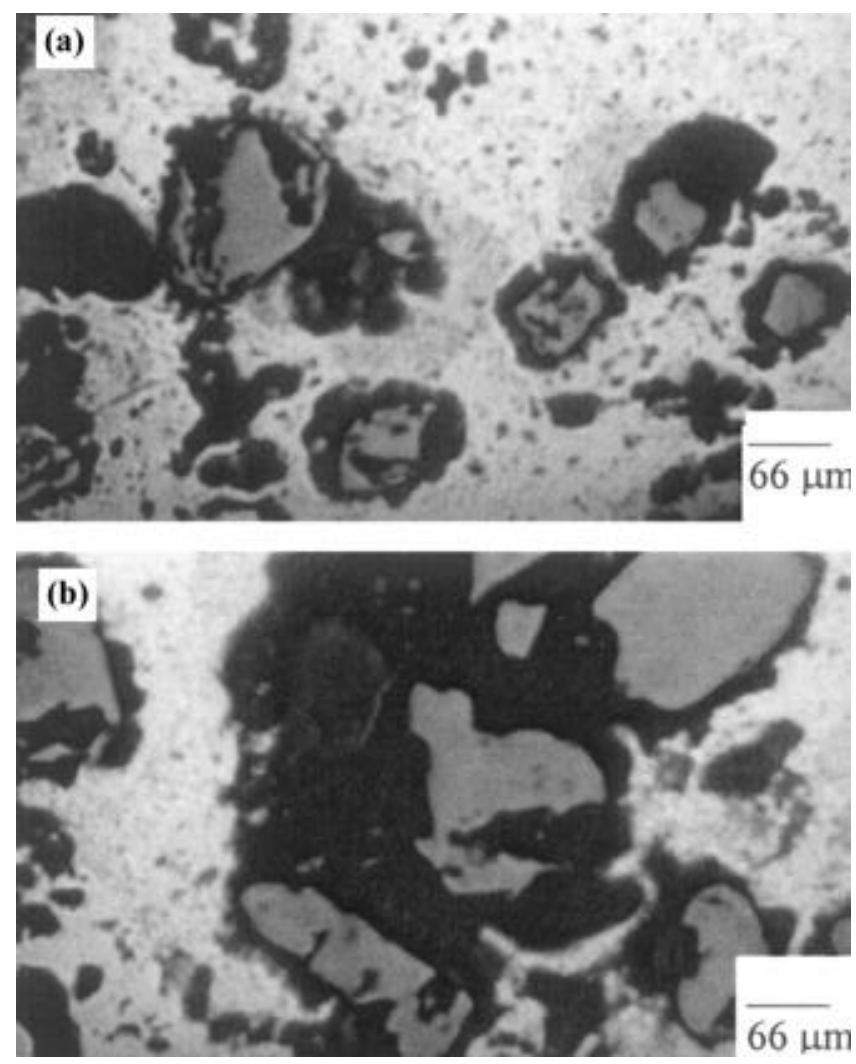

Figure 2. Optical micrograph of as-cast $\mathrm{Al}-2 \mathrm{Mg}-11 \mathrm{TiO}_{2}$ composite: (a) top and (b) bottom of the casting.

Table 1. Results of density measurements.

\begin{tabular}{|c|c|c|c|c|c|}
\hline \multirow[b]{2}{*}{ Parameter } & \multicolumn{3}{|c|}{ As-cast } & \multirow[b]{2}{*}{ Hot rolled } & \multirow[b]{2}{*}{ Cold rolled } \\
\hline & Top & Centre & Bottom & & \\
\hline Density ( $\mathrm{g} / \mathrm{cc})$ & $2 \cdot 29$ & $2 \cdot 43$ & $2 \cdot 52$ & $2 \cdot 65$ & $2 \cdot 68$ \\
\hline$V_{\mathrm{f}}$ of porosity $(\%)^{*}$ & $18 \cdot 0$ & $13 \cdot 0$ & 9.7 & $5 \cdot 1$ & $4 \cdot 0$ \\
\hline
\end{tabular}

*The volume fraction of porosity was calculated assuming that the distribution is uniform throughout the matrix. 


\subsection{Physical properties}

Figure 5 shows the variation of electrical resistivity with temperature for as-cast composite and the base alloy (Al$2 \mathrm{Mg}$ ). It was observed that electrical resistivity of the alloy increased with the addition of ceramic particles. This was due to the low conductivity of rutile particle. Both the base alloy and the composite showed a linear rise of resistivity with temperature at the rate of $0.011 \mu \mathrm{m} /{ }^{\circ} \mathrm{C}$ up to $360^{\circ} \mathrm{C}$, where a peak was observed only in case of composite (figure 5a). Further, the isothermal resistivity measurement of $\mathrm{Al}-2 \mathrm{Mg}-11 \mathrm{TiO}_{2}$ composite done at $360^{\circ} \mathrm{C}$ showed that the phase transformation was over in $8 \mathrm{~min}$ (figure $5 \mathrm{~b}$ ). DSC measurement showed a broad exothermic peak with its onset at $375.52^{\circ} \mathrm{C}$ and peak at $386.83^{\circ} \mathrm{C}$ (figure 6). These peaks indicate phase transformation. There was a difference of about $15^{\circ} \mathrm{C}$ in the onset values between the electrical resistivity and DSC measurements. This could be because electrical resistivity measurements are more sensitive to the changes at atomic level, whereas the DSC peaks correspond to bulk phenomena and hence the response was less sensitive. The XRD results of the composite aged at $300^{\circ} \mathrm{C}$ and $400^{\circ} \mathrm{C}$ are shown in figures $7 \mathrm{a}$ and $\mathrm{b}$, respectively. In the composite aged at $400^{\circ} \mathrm{C}, \mathrm{Al}_{3} \mathrm{Ti}$ was present whereas in the composite aged at $300^{\circ} \mathrm{C}$, it was absent. This indi-
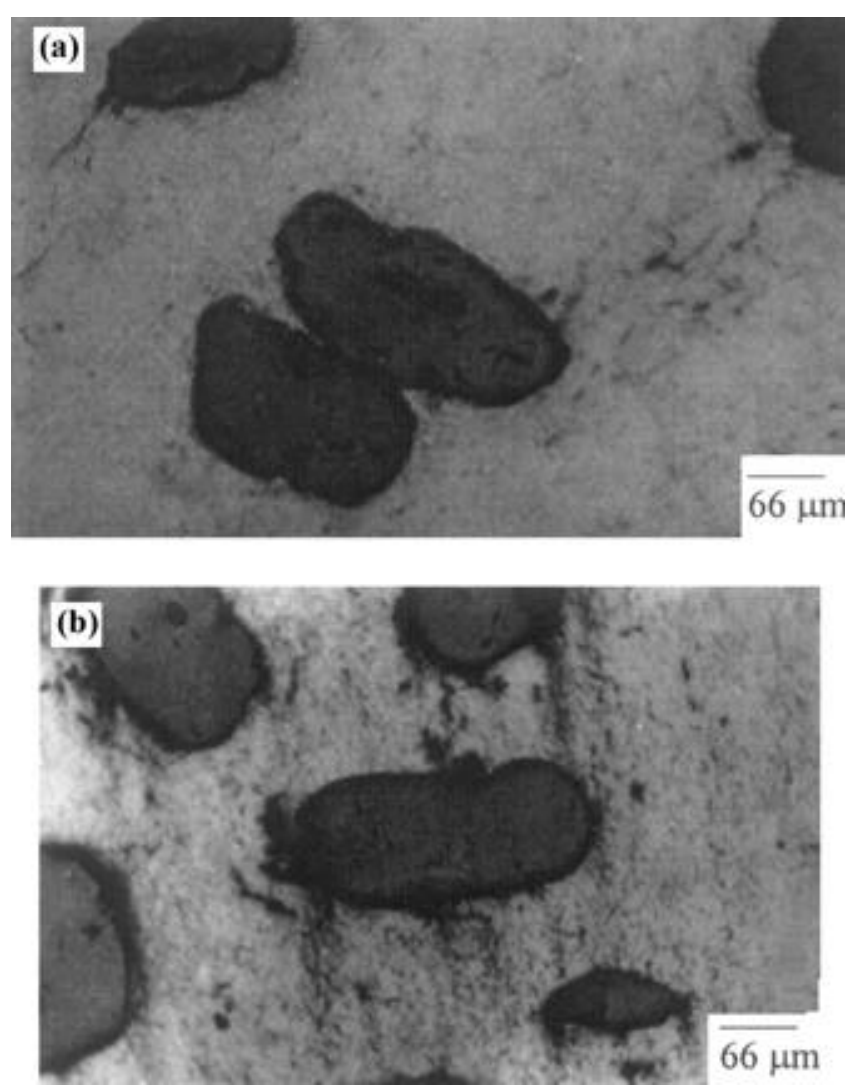

Figure 3. Optical micrograph of $\mathrm{Al}-2 \mathrm{Mg}-11 \mathrm{TiO}_{2}$ composite: (a) hot rolled and (b) cold rolled. cates that $\mathrm{Al}_{3} \mathrm{Ti}$ phase was formed due to an in situ reaction between $\mathrm{Al}$ and rutile particles. This has also been observed by the presence of exothermic peak in DSC studies and deviation in linearity during electrical resistivity measurement.

\subsection{Mechanical property}

The study on hardness measurements revealed that the addition of rutile particles tend to increase the hardness of as-cast composites (43.2 VPN) as compared to the base alloy (39.2 VPN). The hardness of the composite increased appreciably with mechanical working. The hardness of cold rolled and hot rolled composites was 84 VPN and 78 VPN, respectively. The effect of ageing on hardness of the cold rolled composite is shown in figure 8 . The decay in hardness was more rapid in case of composite aged at $400^{\circ} \mathrm{C}$ vis-à-vis with those aged at $300^{\circ} \mathrm{C}$. The hardening mechanism in the composite is due to matrix strengthening resulting from cold working. The ageing curve indicated that the decrease in hardness with time is due to softening of the matrix. To understand the effect of precipitation of $\mathrm{Al}_{3} \mathrm{Ti}$ phase on the tensile properties of the composite, ageing of cold rolled samples was carried out at $300^{\circ} \mathrm{C}$ (below onset of phase transfor-

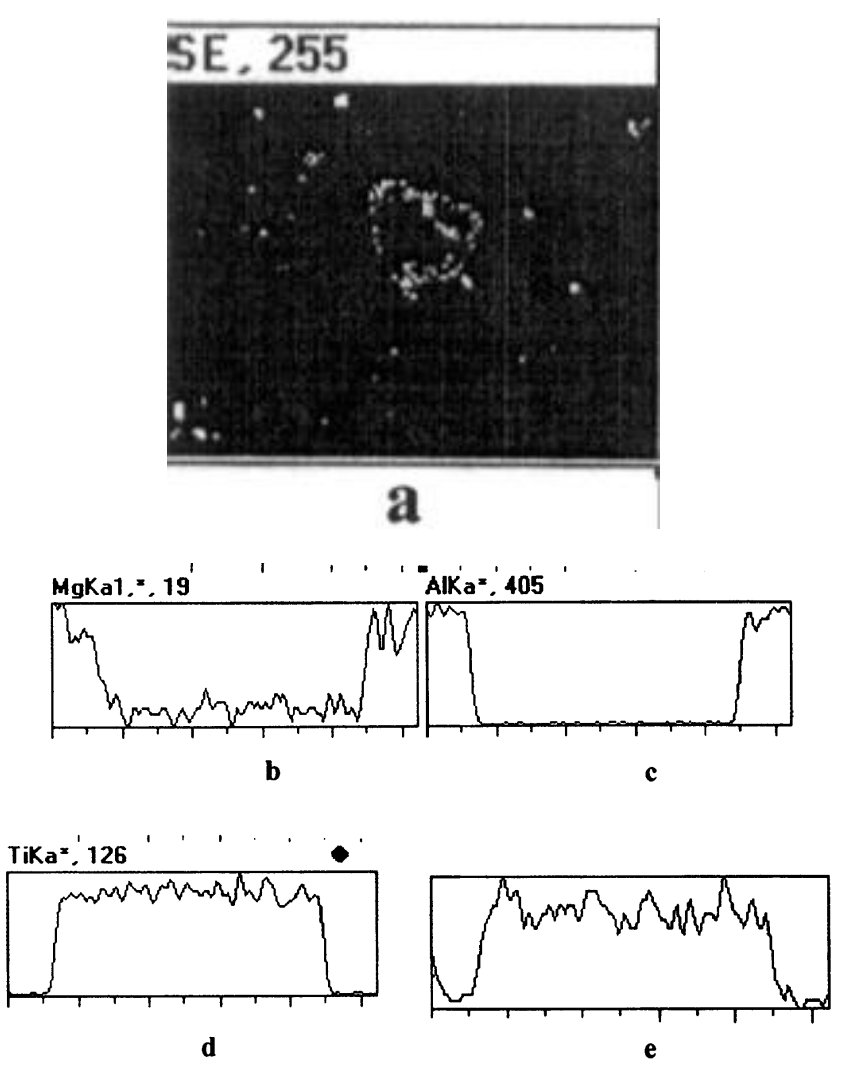

Figure 4. Line profile of stir cast $\mathrm{Al}-2 \mathrm{Mg}-11 \mathrm{TiO}_{2}$ composite: a. back scattered electron image, b. $\mathrm{Mg}, \mathbf{c}$. Al, d. Ti and e. O. 
mation temperature) and $400^{\circ} \mathrm{C}$ (above onset of phase transformation temperature) for 8 min (holding time) and then quenched in oil. Hot rolling of the as-cast composite was done at $400^{\circ} \mathrm{C}$. The result is shown in table 2 . The
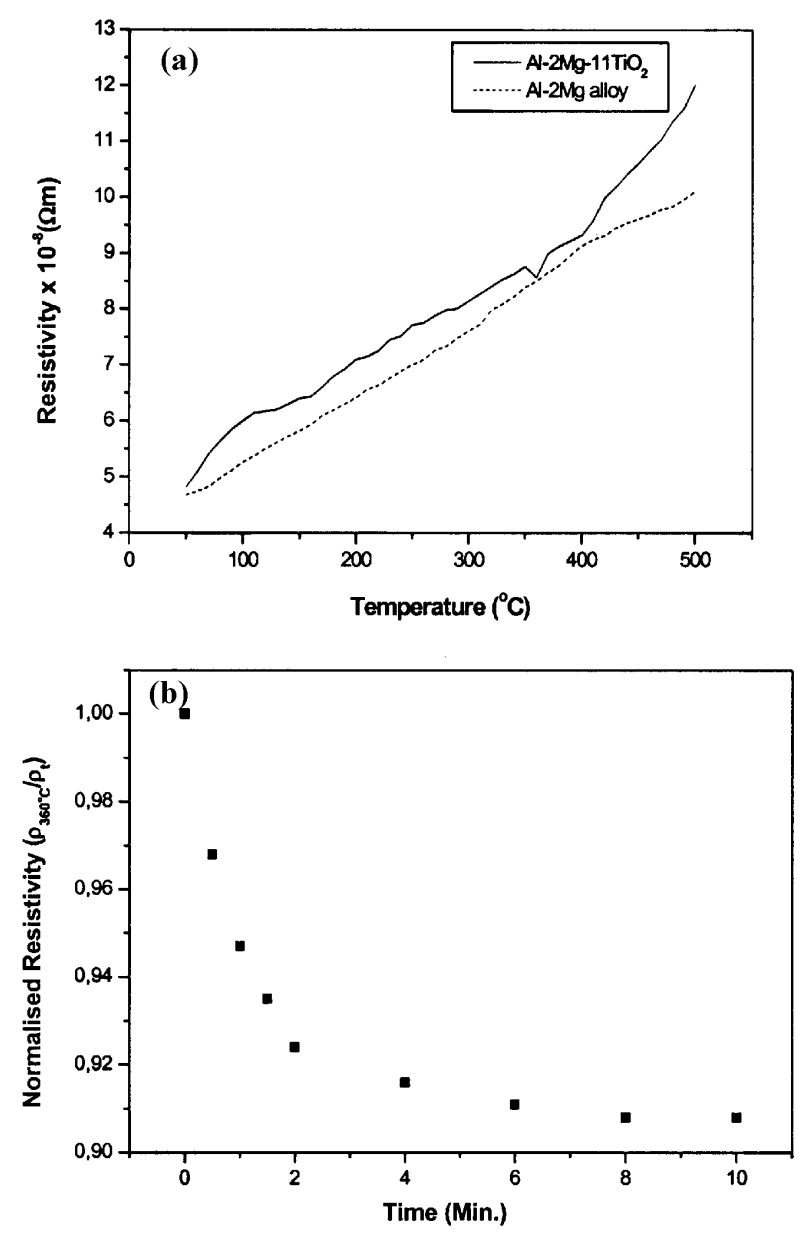

Figure 5. (a) Variation of electrical resistivity with temperature and (b) normalized resistivity plot of as-stir cast Al$2 \mathrm{Mg}-11 \mathrm{TiO}_{2}$ composite.

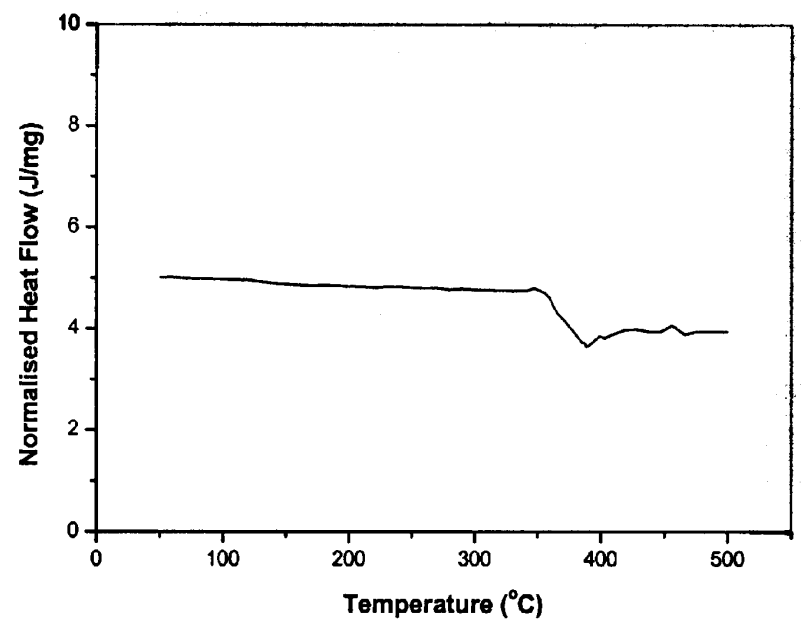

Figure 6. $\mathrm{DSC}$ plot of $\mathrm{Al}-2 \mathrm{Mg}-11 \mathrm{TiO}_{2}$ composite. ultimate tensile strength of the cold rolled composite was slightly higher than the hot rolled sample, but the elongation of former was much lower than the latter. This was because cold rolling resulted in greater degree of work hardening than hot rolling. Although ultimate tensile strength of samples aged at $400^{\circ} \mathrm{C}$ was little higher than that aged at $300^{\circ} \mathrm{C}$, the increase in ductility of composite aged at $400^{\circ} \mathrm{C}$ over the composite aged at $300^{\circ} \mathrm{C}$ was remarkably high. This showed that precipitation of $\mathrm{Al}_{3} \mathrm{Ti}$ particles might have played a vital role in strengthening the interface that lead to the better performance of the composite aged at $400^{\circ} \mathrm{C}$. However, further investigations are needed in this direction.

The fractographic analysis of fractured sample aged at $400^{\circ} \mathrm{C}$ revealed that the crack had nucleated at the particle matrix interface (figure 9) and then propagated through the matrix by inter void coalescence. Similar obser-
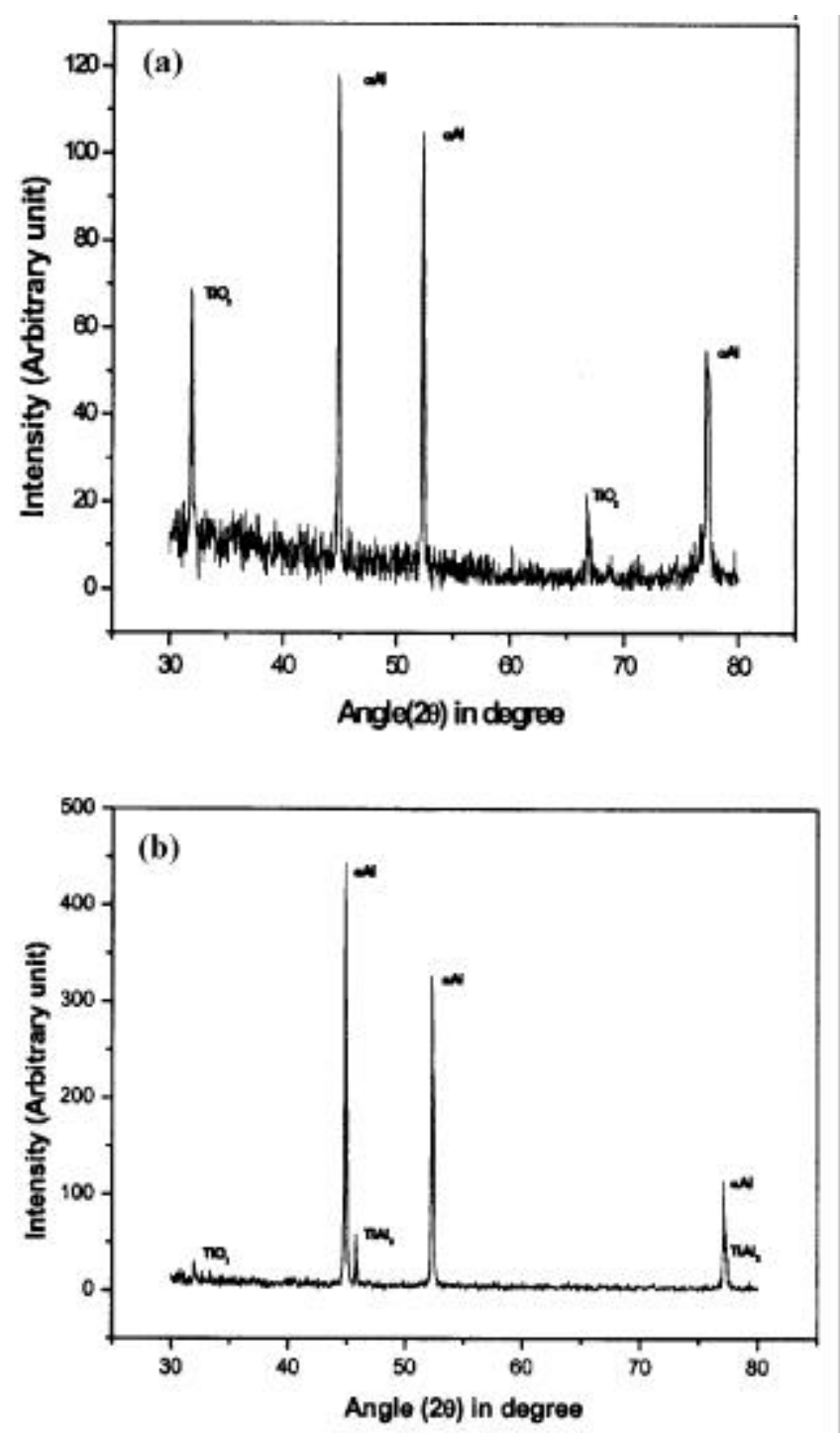

Figure 7. $\mathrm{XRD}$ plot of $\mathrm{Al}-2 \mathrm{Mg}-11 \mathrm{TiO}_{2}$ composite aged at (a) $300^{\circ} \mathrm{C}$ and (b) $400^{\circ} \mathrm{C}$. 
Table 2. Tensile properties of $\mathrm{Al}-2 \mathrm{Mg}-11 \mathrm{TiO}_{2}$ composites at different conditions.

\begin{tabular}{lcccccc}
\hline & \multicolumn{2}{c}{ Rolling } & & \multicolumn{2}{c}{ Ageing after cold roll for $8 \mathrm{~min}$} \\
\cline { 2 - 3 } \cline { 5 - 6 } Tensile properties & Hot & Cold & & $300^{\circ} \mathrm{C}$ & $400^{\circ} \mathrm{C}$ \\
\hline U.T.S. (MPa) & 76 & 108 & & 95 & 113 \\
Elongation (\%) & 4.7 & 2.5 & & 5.4 & 6.3 \\
\hline
\end{tabular}

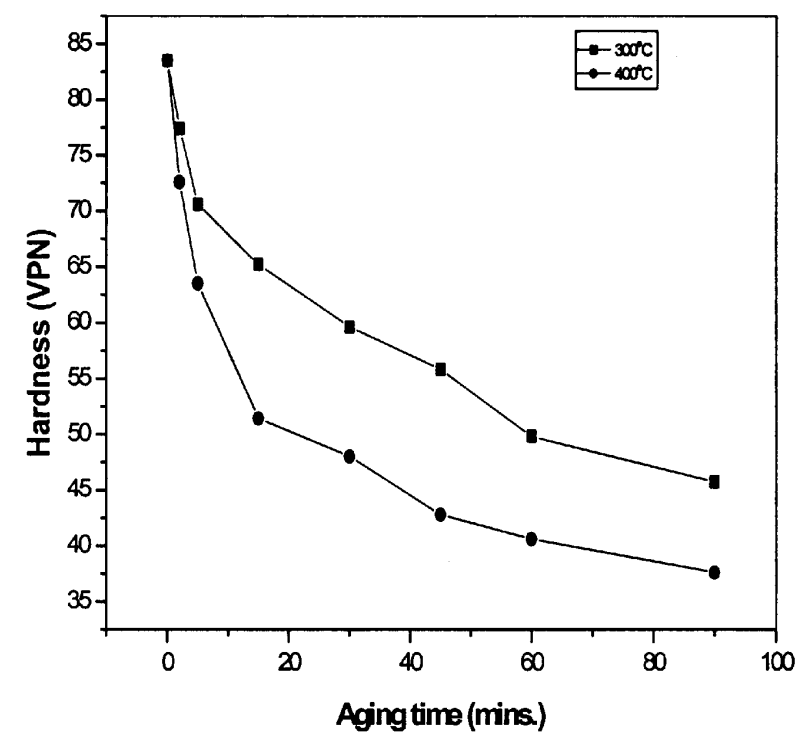

Figure 8. Ageing behaviour of $\mathrm{Al}-2 \mathrm{Mg}-11 \mathrm{TiO}_{2}$ composite.

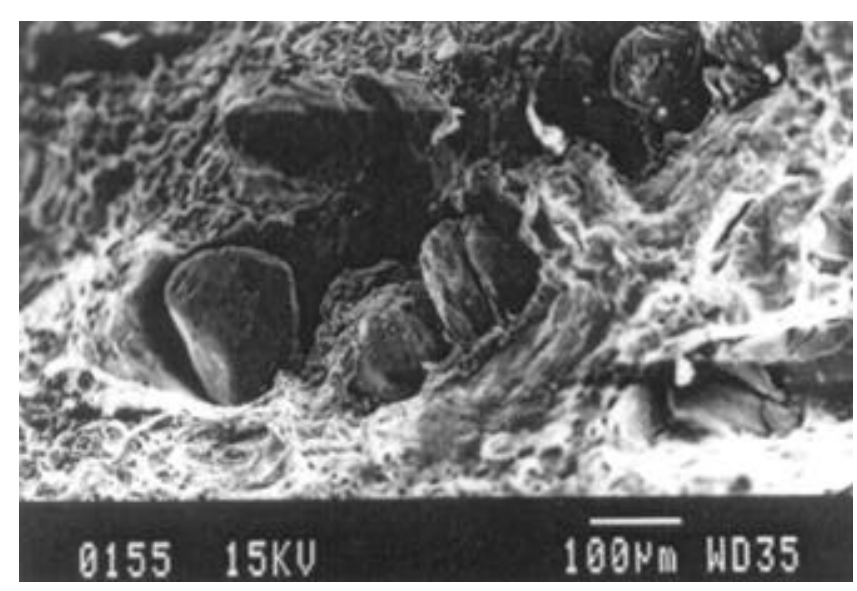

Figure 9. SEM fractograph of $\mathrm{Al}-2 \mathrm{Mg}-11 \mathrm{TiO}_{2}$ composite aged at $400^{\circ} \mathrm{C}$.

vations are reported in the literature (Bhanuprasad et al 1995). The high percentage of elongation was supported by the presence of dimples on the fractured sample of the composite (Vanstone et al 1985).

\section{Conclusions}

$11 \mathrm{wt} \%$ of $\mathrm{TiO}_{2}$ could be successfully incorporated into the $\mathrm{Al}-2 \mathrm{Mg}$ melt by vortex method. Greater degree of segregation of $\mathrm{TiO}_{2}$ has been observed at the top and bottom of castings. Microvoids are observed in the particles enriched zone. A phase transformation has been observed during the resistivity and DSC measurements owing to the precipitation of $\mathrm{TiAl}_{3}$ phase. Cold and hot rolling of the composite is successfully carried out to $40 \%$ and $50 \%$ reduction, respectively. Hardness of the composite is greater than the base alloy, which can be attributed to the presence of higher dislocation density in the matrix due to the difference in thermal properties between the matrix and dispersoids. The improved tensile behaviour of cold rolled composite aged at $400^{\circ} \mathrm{C}$ could be due to the precipitation of the $\mathrm{Al}_{3} \mathrm{Ti}$ phase.

\section{Acknowledgement}

One of the authors (SKC) is grateful to CSIR, New Delhi, for providing financial assistance to carry out this work.

\section{References}

Alonso A, Paamies A, Narciso J, Garcia-Cardovilla C and Louis E 1993 Metal. Trans. A24 1423

Bhanuprasad V V, Staley M A, Ramakrishnan P and Mahajan Y R 1995 Key engineering materials (Switzerland: Transtech Publication) 104-107 p. 495

Chu Shuangjie and Wu Renjie 1999 Compos. Sci. \& Technol. 59157

Maity P C, Chakraborty P N and Panigrahi S C 1993 Scr. Met. Mater. 28549

Maity P C, Chakraborty P N and Panigrahi S C 1995 J. Mater. Process. \& Technol. $\mathbf{5 3} 857$

Rohatgi P K 1991 J. Mater.

Rohatgi P K, Asthana R and Das S K 1986 Int. Met. Rev. 31 115

Vanstone R H, Cox Jr T B and Psioda J A 1985 Int. Met. Rev. 30157 